\title{
Introduction of e-commerce at enterprises as a driver of digital economy
}

\author{
Svetlana Drobyazko ${ }^{1^{*}}$ \\ ${ }^{1}$ Doctor of Economic Sciences, Professor, President European Academy of Sciences, 71-75 Shelton \\ Street Covent Garden, London, United Kingdom.
}

\begin{abstract}
It is proved that the introduction of electronic commerce is an effective tool to improve enterprises' efficiency and the ability to access global markets. The advantages and disadvantages of using e-commerce for the subjects of economic relations: consumers, enterprises, and the state have been analyzed. The goal of the work is the development of a theoretical and methodological framework, substantiation of the directions of functioning and regulation of e-business enterprises. Statistical evaluation of e-commerce development has been used as the main research method. Peculiarities of the use of acquiring as a service of technological information services for settlements on transactions made using electronic means of payment in a payment system have been considered. Based on the results of the study, the use of acquiring a small business with a view to its development of Digital Economy has been proposed. As a conclusion from the results of the study, the recommended means of ensuring economic security in the field of electronic commerce: two-step authentication, negative lists, customer order history, credit history verification, payer authentication, fraud modeling, fingerprint devices, card confirmation numbers, and address verification services.
\end{abstract}

\section{Introduction}

The development of the digital economy consists in creating market incentives, motivations, demand and forming needs for the use of digital technologies, products and services among the Ukrainian industrial sectors, spheres of life, business and society for their effectiveness, competitiveness and national development, growth in the production of high-tech products and the well-being of the population. The digital economy is based on information and communication and digital technologies, the rapid development and spread of which already today affect the traditional (physically analogous) economy, transforming it from one that consumes resources to an economy that creates resources. It is the data that is the key resource of the digital economy, it is generated and provides electronic communication interaction due to the functioning of electronic digital devices, tools, and systems.

Digitization leads to a significant transformation of markets. This is especially noticeable in the trade sector. In connection with the continuous development of

* Corresponding author: svetlana.drobyazko@yahoo.com 
information networks, new public institutions, such as e-commerce, have appeared. The rapid development of modern information technologies and the World Wide Web plays an important role in various spheres of life, significantly contribute to the activation of civil and economic development, and guide entrepreneurship towards globalization.

In modern conditions, e-commerce is an integral element of the rapid sale of goods and services between business entities, aiming to reduce costs and time and expand the market and generate additional profit. Today, e-commerce, like any other form of economic relations, is in the rapid development of information and financial instruments, is continuously being improved, and new crimes appear in this area. The leading countries in which this economic phenomenon has appeared and is developing rapidly are the United States of America and Canada [1]. Europe lags behind North American countries in ecommerce by about a year, and the interval between countries in the post-Soviet space and Europe is 3-5 years [10]. However, the real situation is more uncertain.

While Western companies have already exhausted all the reserves of traditional ways of increasing efficiency and using e-commerce are fighting for several percent of growth, our national enterprises have more growth opportunities. Strengthening labor discipline or introducing an effective automated accounting system, you can get a more significant result than electronic seven commerce [5]. But it is possible to combine with these steps the creation of an e-commerce system while simultaneously implementing the set of measures that Western companies have consistently resorted to for several decades.

E-commerce is the sale or purchase of goods or services through computer networks using methods specifically designed to receive or place orders [6-7]. E-commerce must simplify the search for contractors, especially for small and medium enterprises, which are, as you know, the drivers of economic growth. The subject of electronic commerce can be any form of conducting commercial operations, for example, trade, distribution agreements, commercial representation, and agent relations, factoring, leasing, construction of industrial facilities, provision of advisory services, engineering, purchase or sale of licenses, investment financing, banking services, insurance and other forms of industrial or business cooperation [8].

All processes that make up the content of an electronic transaction, for example, market study, search for a commercial partner, payment transactions, risk insurance, etc. are also the subject of e-commerce [11]. According to the generally accepted interpretation of UNCITRAL, these forms of economic activity are now referred to as electronic commerce [3]: Electronic Data Interchange, EDI; Electronic Funds Transfer, EFT; e-trade; e-cash; emarketing; e-banking; e-insurance.

However, with all the variety of research in this area, some theoretical and methodological aspects of management information processes, which are necessary to improve the efficiency and quality of enterprise management and the development of its activities, are insufficiently studied. In particular, the issues related to the evaluation of the management information process based on technical, qualitative, and safety indicators and those that determine their effectiveness, which can be used as a basis for the criteria of sound management decisions, need to be clarified. The relevance and unresolved issues of methodological and applied nature led to the choice of topic and determined the study's goal and logic. The goal of the work is the development of the theoretical and methodological framework, substantiation of the directions of functioning and regulation of e-business enterprises.

\section{Method}

The theoretical and methodological basis of the work is the fundamental provisions of economic theory and management. To achieve this goal, general and special research 
methods have been used in work: abstract-logical method, systematic approach, and analysis and synthesis methods, to clarify the concept of the information management process, to determine its characteristics and system of evaluation indicators; graphic one to visualize the results.

To determine the factors to ensure the effectiveness of the formation of the information process of industrial enterprise management, taking into account all the advantages of mathematical modeling, the method of main components is used. In contrast to simple factor analysis methods, it allows identifying a sufficient and comprehensive number of characteristic factors of the phenomenon under study.

\section{Results and discussion}

The development of e-commerce has a stabilizing effect on the development of the economy due to the accelerated pace of creating a single information space: mechanisms of information interaction are being developed for almost all subjects of the world market; decentralization of resources, stimulating the independent development of market entities; acceleration of cash flow due to the use of electronic payment systems; a decrease in speculative capital (among non-producer intermediaries) and, consequently, an increase in investment in the manufacturing sector; creation of conditions for open competition in the markets of goods and services; acceleration of the process of market promotion of new goods, services and bringing them in a convenient form to the consumer. Characteristic features of the use of electronic commerce for subjects of economic relations are presented in Table 1.

Table 1. Comparative characteristics of the use of electronic commerce for subjects of economic relations.

\begin{tabular}{|c|c|}
\hline Advantages & Disadvantages \\
\hline \multicolumn{2}{|c|}{ For the consumer } \\
\hline $\begin{array}{l}\text { Decrease in the price of goods (services) } \\
\text { when interacting with the seller; } \\
\text { reduction of time for choosing and } \\
\text { making a purchase; free and global } \\
\text { access to international markets; } \\
\text { optimization of commodity flows, } \\
\text { exemption from intermediaries; ability } \\
\text { to create goods (services) with specific } \\
\text { configurations. }\end{array}$ & $\begin{array}{l}\text { Low degree of permeability of the Internet } \\
\text { (especially in the regions) compared with } \\
\text { developed countries; high degree of distrust of } \\
\text { manufacturers regarding quality and safety, } \\
\text { because all contacts occur indirectly; limited } \\
\text { opportunities to use international electronic } \\
\text { payment systems; imperfect legal framework } \\
\text { for regulating consumer protection in the field } \\
\text { of electronic commerce. }\end{array}$ \\
\hline \multicolumn{2}{|r|}{ For the enterprise } \\
\hline $\begin{array}{l}\text { Development of a competitive } \\
\text { environment and new distribution } \\
\text { channels; savings on costs associated } \\
\text { with the maintenance of employees, } \\
\text { office, warehouse; global presence in all } \\
\text { markets; effective direct and operational } \\
\text { interaction with the end user. }\end{array}$ & $\begin{array}{l}\text { Difficulties in protecting copyright and } \\
\text { intellectual property; part of the population in } \\
\text { the regions remains unreached; lack of } \\
\text { customer awareness of goods or services; free } \\
\text { access to special characteristics of goods; } \\
\text { fierce competition, including international; } \\
\text { significant risks when choosing a pricing } \\
\text { strategy. }\end{array}$ \\
\hline
\end{tabular}


Interest in the development of e-commerce for the perfect business analysis and marketing research; use of mechanisms for unshadowing e-commerce; development of innovative business models of e-commerce; the country's economy will be able to move to a higher level thanks to the development of e-commerce. llegal business development; disagreements of state legislation with international; imperfect legislative regulation of business processes through the rapid pace of e-commerce development and other factors; destruction of a link of intermediaries.

Today, e-commerce has not only confidently entered ordinary citizens' lives but has also become a competitive advantage in international trade for those states that stimulate its development. E-commerce gives businesses new opportunities to make money in the wake of growing demand from consumers interested in online shopping. Today, most countries of the world are actively using modern e-commerce tools. The rating of countries by the use of e-commerce is given in Table 2 .

Table 2. Rating of countries by the use of e-commerce.

\begin{tabular}{|c|c|c|c|c|c|}
\hline No & $\begin{array}{l}\text { Leading } \\
\text { country }\end{array}$ & $\begin{array}{l}\text { The volume } \\
\text { of e-commerce } \\
\text { market, bln USD }\end{array}$ & $\begin{array}{c}\text { Shopping using } \\
\text { mobile } \\
\text { phone } \\
\text { (smartphone) } \\
\%\end{array}$ & $\begin{array}{c}\text { Shopping } \\
\text { using a desktop } \\
\text { computer } \\
\%\end{array}$ & $\begin{array}{l}\text { Shopping } \\
\text { using } \\
\text { tablet } \%\end{array}$ \\
\hline 1. & China & 562.66 & $33 \%$ & $67 \%$ & - \\
\hline 2. & United States of & 349.06 & $15 \%$ & $72 \%$ & $13 \%$ \\
\hline 3. & United Kingdom & 93.89 & $16.5 \%$ & $71.4 \%$ & $12.1 \%$ \\
\hline 4. & Japan & 79.33 & $46 \%$ & $48 \%$ & $6 \%$ \\
\hline 5. & Germany & 74.46 & $16.2 \%$ & $72.3 \%$ & $11.5 \%$ \\
\hline 6. & France & 42.46 & $11.1 \%$ & $80.8 \%$ & $8.1 \%$ \\
\hline 7. & $\begin{array}{c}\text { Republic of Korea } \\
\text { (South Korea) }\end{array}$ & 36.76 & $50 \%$ & $49 \%$ & $1 \%$ \\
\hline 8. & Canada & 28.77 & $8.7 \%$ & $83.7 \%$ & $7.6 \%$ \\
\hline 9. & Russia & 20.30 & $8 \%$ & $80 \%$ & $12 \%$ \\
\hline 10. & Brazil & 18.80 & $8 \%$ & $88 \%$ & $4 \%$ \\
\hline
\end{tabular}

It is important to note that the supply and demand for goods and services are set directly on the Internet. In other words, the traditional mechanism of selling goods is changing, the selection of which is made directly on the Internet, where the corresponding transactions and payments are made. Therefore, the development of technologies and information networks has revolutionized communications and significantly influenced several economic processes related to business development.

Types of electronic means of payment are divided into 1) network-based (trade on the Internet). The Internet enables domestic companies to enter the world market, expand sales channels, and connect suppliers and buyers into a single system. The turnover of ecommerce amounts to such significant figures that it is impossible to ignore or underestimate the importance of this relatively new sector of the economy. It is impossible to do large-scale business in current conditions without the use of information technologies. In this context, it should be borne in mind that with the growth of online sales, there is an increase in online payments. Thus, the Internet has become a leading, key technology of modern economic interaction. E-commerce payment systems somehow use non-cash payments and electronic money in their payments. 2) card-based (plastic cards as a tool of 
payments and crediting). A payment card is one of the types of non-cash payments, a means of identifying its owner, etc. The percentage of non-cash payments using payment cards in Ukraine is presented in Figure 1.

Today the main direction of the state policy of Ukraine in the area of electronic payment systems is: to stimulate the expansion of non-cash payments and the development of payment infrastructure, which is to reduce the percentage of cash payments, which will increase budget revenues without increasing tax rates. At the same time, the spread of electronic payments is associated with a wide range of risks. The successful operation of a payment system has always depended on the confidence of participants in payment instruments. Even small doubts or problems in a system's operation have often led to a complete breakdown of the system and the transition to alternative payment instruments.

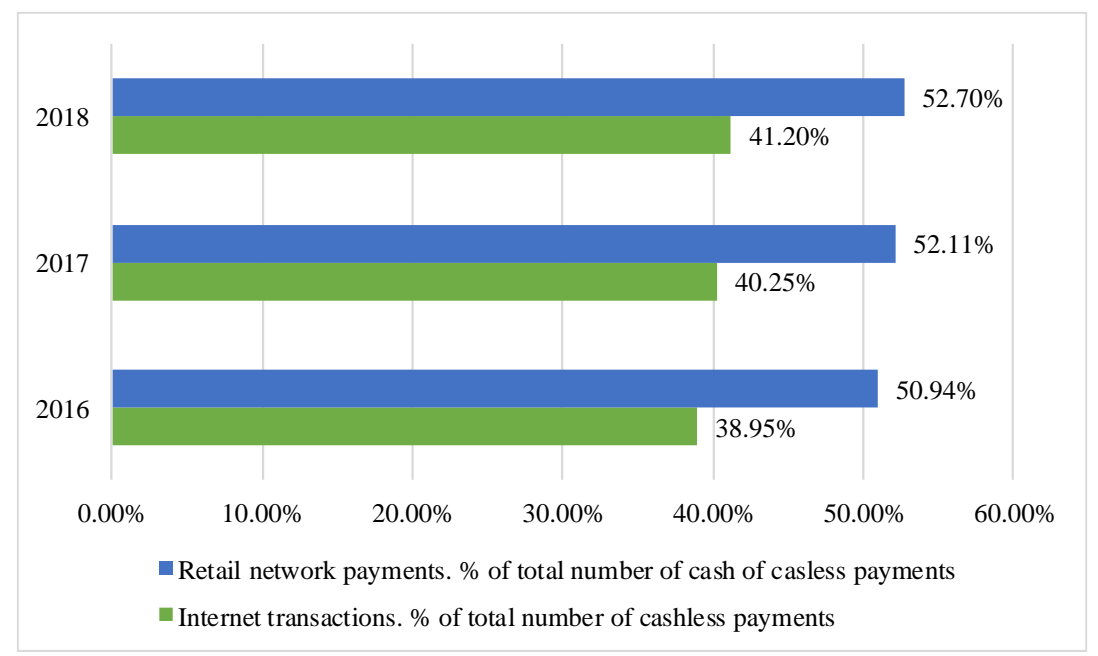

Fig. 1. Number of non-cash payments in retail chains and transactions on the Internet in Ukraine. constructed by the author on the basis of [9]

Accordingly, for electronic payments, which are "dematerialized" as much as possible, the system's trust and reliability are even more acute. In electronic payment systems, the system operation is related to the uninterrupted operation and critical infrastructure quality, making them much more vulnerable than regular payments. Also, an essential factor is the protection of customers from fraud.

One of the services for servicing payments by a payment card is acquiring - a service of technological information services for settlements on transactions made using electronic means of payment in the payment system. At first, the service of acquiring was quite simple, even primitive. In so doing, for cashless payments, cashiers used an intricate mechanical device, the so-called "imprinter," with which a slip was removed from the payment card with the necessary details. However, this procedure was not entirely convenient and safe since the lack of communication with a banking institution did not allow the seller to determine the availability of the required amount on the buyer's payment card. Therefore, the next invention was an electronic terminal - a modern device that directly communicates with the bank when making a payment.

Among the types of acquiring, we can distinguish the following: ATM acquiring appeared first in our country and includes: payment terminals and ATMs, allowing you to replenish and withdraw cash at any convenient time; trading acquiring includes operations are conducted through special POS-terminals. During the execution of such an action, funds are transferred to the account of the entrepreneur. At the same time, the service provider withholds a certain amount, the size of which is determined by the financial institution. 
Changes in rates and the abolition of limits on operations are tightly tied to the enterprise; mobile acquiring - this system is primarily aimed at owners of mobile devices. Thanks to it, a payment transaction option is possible when using a smartphone. Mobile acquiring eliminates the need to bind to a particular place of trade and allows you to equip all employees of the company with terminals, even those working outside the office; Internet acquiring as a component of e-commerce is the activity of a credit institution (acquiring bank), which includes settlements with e-commerce organizations on transactions made using bank cards on the Internet.

Under the current conditions in Ukraine, expanding e-trading platforms is ahead of the creation of mechanisms that properly regulate their activities, thereby creating conditions for the development of criminal schemes. But this problem exists not only in our state. The main challenge for most e-commerce players worldwide is the growing requirements to the process component of e-commerce, the need for multi-channel promotion, the security of purchase, and buyers' personal and payment data. In Figure 2, criminal offenses in the area of payment systems and e-commerce in Ukraine are presented.

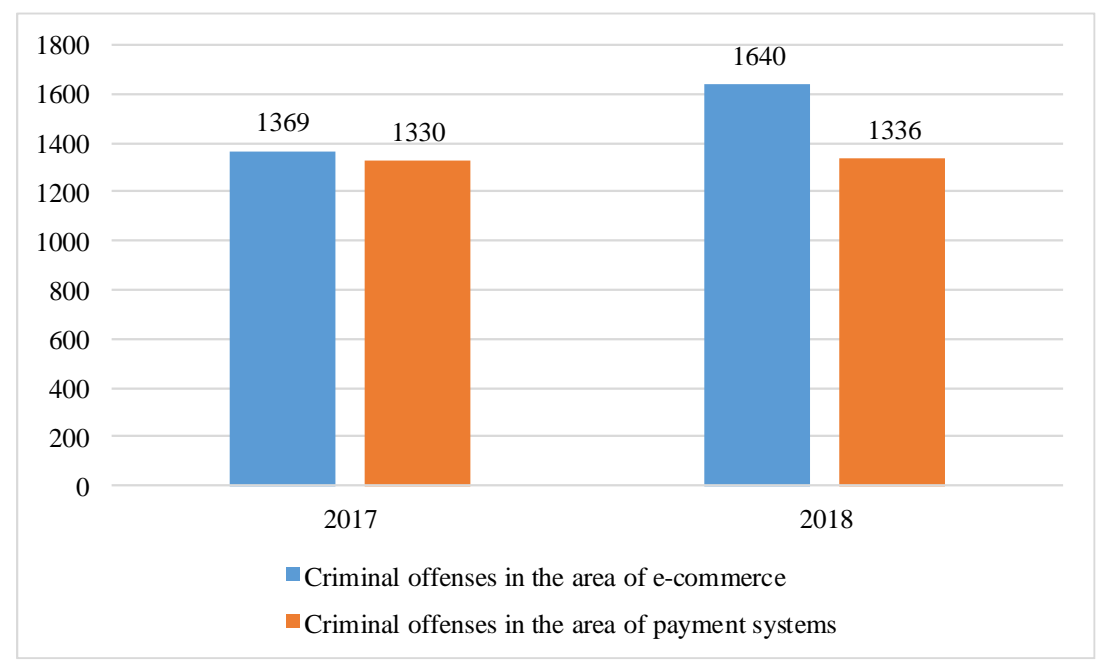

Fig. 2. The number of non-cash payments in retail chains and transactions on the Internet in Ukraine, constructed by the author based on [4]

According to Figure 2, the level of criminal offenses in electronic payment systems and e-commerce in Ukraine in 2018 compared to 2017 has increased insignificantly. Today, it needs both adequate protection and proper investigation in the above areas. Today, there are such technologies for protecting Internet acquiring: 1) PCI DSS for processing centers (banking and independent) payment card security requirements. The standard is approved by Visa, MasterCard, American Express, JCB, Discover payment systems. To be eligible for Internet acquiring, an organization must have a PCI DSS compliance certificate; 2) SSL encryption protocol to ensure secure communication between the customer and the server, on which he/she enters data for identification [14]; 3) 3D Secure for VISA cards, Secure Code for MasterCard - protocol for additional protection of card payments developed by VISA system. In addition to the card data, the customer enters an additional password issued by the issuing bank to participate in the 3D Secure program [13].

At the moment, it is safe to say that unique protocols such as $3 \mathrm{D}$-Secure, Secure Code, etc., which provide a high degree of security of acquiring payments, usually exceed the level of security of most existing and actively used electronic payment systems. Therefore, customers who follow the proposed rules for making payments using acquiring may not be 
afraid for the safety of their own money. This factor is duly assessed by many potential service consumers, one of the essential arguments for further spread and growing use of Internet acquiring.

Despite its worldwide popularity, Ukraine acquiring today is still at the stage of development. At the same time, it has recently become one of the priorities and most developed areas of the card business in Ukraine. Thus, the country's total number of issued bank cards has already exceeded the population with a coverage ratio of more than one. Indeed, in developed European countries and the United States, this figure is two times higher, and in some of them even four times higher.

One of the important factors of development is the general level of the population's financial and banking culture. It has grown significantly in recent decades, and today a growing number of people prefer cashless payment. Today, the card is accepted as a convenient tool for daily use of own account and access to the bank's credit resources. It is also advantageous for companies to simplify the procedure for paying for their goods and services and the process of delivering money to their bank account.

However, as practice shows, most issues in the above area are still unresolved, which violates the rights of individuals or legal entities, and hinders the introduction of the digital economy in Ukraine, and hence cross-border e-commerce. Ukrainian business operators, from time to time, face systemic problems of currency control. Western employers are now in a better position than Ukrainian e-commerce companies. To facilitate exports and expand participation in international trade, including e-commerce, experts suggest adapting currency rules, attitudes to e-money, and virtual money as much as possible to European legislation.

Electronic money helps increase the speed of cross-border transactions and is widely used in the US and the EU. It is worth noting that virtual currencies are increasingly used in e-commerce. For example, bitcoin is now accepted by many online platforms worldwide (the large American mass-market Overstock, ticket agencies CheapAir, Expedia, etc.).

However, Ukraine still does not have an exact legal status for virtual money. Ukraine can benefit from foreign jurisdictions (USA, Canada, Japan, etc.), which define the concept of virtual currencies to combat money laundering and thus provide a basis for their legal use. One of the most important conditions for the effective use of the e-commerce system is to provide an efficient, inexpensive, and secure means of making payments. There are a sufficient number of ways to communicate on the Internet. Cryptography with a public key is becoming popular now. The selection of the best means of payment protection should be entrusted to specialists. The organization of e-commerce should be based on traditional legal norms and rules and provide for the development of new specialized institutions and procedures.

In addition to barriers in the areas included in the EU regulatory framework for ecommerce, barriers to the convergence of e-commerce also exist in areas of law not covered by the Directives. Such barriers include, for example, differences in the tax legislation of member states, difficulties in complying with different consumer protection requirements, problems related to the settlement of cross-border legal disputes, market differentiation established by copyright holders, differences between national approaches to enforcement environment regarding the handling of harmful or useless information, etc. [7]. The main tools used to detect fraud in North America are presented in Figure 3. 


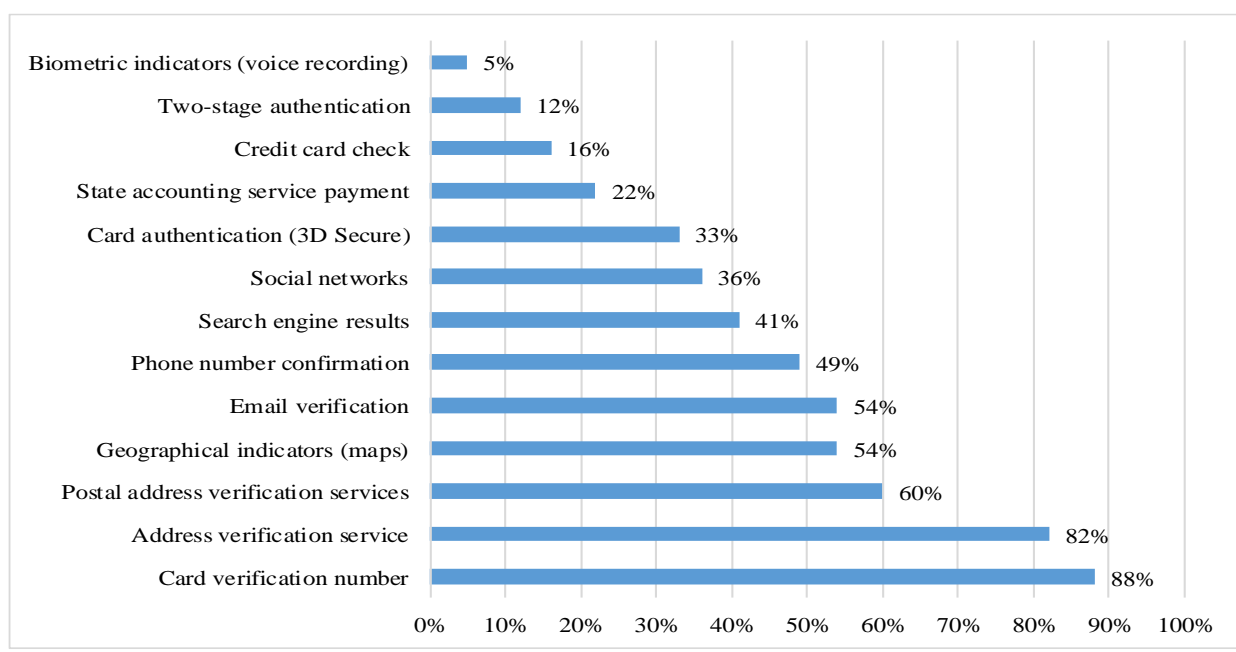

Fig. 3. The main tools used to detect fraud in e-commerce in North America in 2017, constructed by the author based on [2]

Today, small enterprises operate and get used to a cashless payment market more slowly than medium and large corporations. Typically, small enterprises are prevented from switching to acquiring by high prices for equipment; however, some banks offer them POSterminals at affordable prices and other benefits when concluding acquiring agreements. The main advantages of using acquiring for small businesses are growing in sales, as a client who is allowed to pay with a bank card is ready to buy $20-30 \%$ more. He is spared the need to count the cash, and this gives him a sense of freedom when shopping; POS terminals and acquiring securely protect the company from fraud; acquiring banks consolidate cooperation with small businesses, providing them with benefits and bonuses; the company receives the right to free training for personnel working with cashless terminals. The qualification of employees is growing at no cost for management.

All indications are that switching to an acquiring system for small businesses is extremely beneficial. According to studies [6, 12], paying with a card, buyers spend, on average, $20 \%$ more than in cash. Therefore, thanks to these opportunities, a small business can significantly increase profits.

Issues related to ensuring the necessary security level are conducted through the Internet of financial transactions and payments, which are considered the most relevant. Fears of a sufficiently large number of potential customers to save their funds on bank cards seriously hamper the development of many advanced payment technologies, including Internet acquiring. Therefore, developers of banking acquiring systems pay special attention to security problems.

\section{Conclusion}

In current conditions, the development of electronic commerce significantly affects the state's economic policy, provides an impetus to increase the total volume of production, and contributes to the complete satisfaction of society's needs. The ability to quickly adapt to consumer demand changes, mobility, flexibility, and a rational organizational structure is the universally recognized advantage of small businesses. Today, small enterprises use one such advantage as electronic commerce, which determines the enterprise's innovative and investment attractiveness and efficiency are working with consumers. 
Every year, the level of e-commerce use in the world is rapidly increasing, and at the same time, the number of business entities already in this plane is increasing. However, insufficient regulatory influence by government bodies and the rapid development of information technologies create the prerequisites for an open and unprotected space in the commission of criminal offenses and, consequently, the economy's development.

The analysis showed that most countries are always searching for effective and efficient tools to ensure economic security in the field of electronic commerce. The following are the most significant: 2-step authentication, negative lists, customer order history, credit check, payer authentication, fraud modeling, fingerprint devices, card confirmation numbers, and address verification services. Using the latest tools in data protection and training specialists in e-commerce protection are the next successful steps in implementing and developing a significant economic policy of the state.

Today, in the context of reforming the national economy, it is important for Ukraine to determine the purpose and primary objectives of economic policy to implement security in e-commerce and e-payments because of the formation and movement of financial flows is the blood-forming system. The analysis of the provision of banking services makes it possible to identify the advantages and disadvantages of acquiring as an activity for technical and information services provided to merchants and settlements with them for transactions carried out using unique means of payment. Connecting acquiring guarantees an increase in revenue and allows attracting new customers. This tool is very convenient for all market participants in trade and financial services.

Any company interested in the growth and development of its own business should be aware of the importance of providing the opportunity to pay for goods or services using a plastic card. The analysis of the state of services of technical and information services of settlements on transactions, which are carried out using electronic means of payment in the payment system of Ukraine, indicates the need for further research of acquiring.

\section{References}

1. S. N. Ahmad, M. Laroche, Analyzing electronic word of mouth: A social commerce construct, Int. J. of Inf. Man. 37, 3, 202-213, (2017) https://doi.org/10.1016/j.ijinfomgt.2016.08.004

2. All-in-one e-commerce fraud guide: types, definition, prevention 2018 https://amasty.com/blog/all-in-one-e- commerce-fraud-guide-types-detectionprevention-2018/

3. 3M. P. Cockrill, W. K. Bryant, D. C. Franklin, M. H. McNeely, T. J. Ryan, A. P. Sweet, ..., T. A. Malek, U.S. Patent Application No. 10/163,101, (2018).

4. Cyberpolicy notes an increase in the number of offenses in the field of payment systems and cybersecurity https://cyberpolice.gov.ua/news/kiberpolicziya-vidmichayezbilshennya-kilkosti-pravoporushen-u-sferi-platizhnyx-system-ta-kiberbezpeky-1519/

5. M. Garbowski, S. Drobyazko, V. Matveeva, O. Kyiashko, V. Dmytrovska, Financial Accounting of E-Business Enterprises, Acad. of Acc. and Fin. Stud. J. 23, 2, (2019) https://www.abacademies.org/articles/financial-accounting-of-ebusiness-enterprises8223.html

6. S. Drobyazko, V. Makedon, D. Zhuravlov, Y. Buglak, V. Stetsenko, Ethical, Technological and Patent Aspects of Technology Blockchain Distribution, J. of Leg. Eth. and Regu. Iss. 22, 2S, (2019) https://www.abacademies.org/articles/ethicaltechnological-and-patent-aspects-of-technology-blockchain-distribution-8434.html 
7. A. Durmanov, V. Bartosova, S. Drobyazko, O. Melnyk, V. Fillipov, Mechanism to ensure sustainable development of enterprises in the information space, Entrepr. and Sus. Iss. 7, 2, 1377-1386, (2019) http://doi.org/10.9770/jesi.2019.7.2(40)

8. T. Y. Kim, R. Dekker, C. Heij, Cross-border electronic commerce: Distance effects and express delivery in European Union markets, Int. J. of Elec. Comm. 21, 2, 184218, (2017) https://doi.org/10.1080/10864415.2016.1234283

9. Official data of the National Bank of Ukraine, https://bank.gov.ua/ua/payments

10. E. Turban, J. Outland, D. King, J. K. Lee, T. P. Liang, D. C. Turban, Electronic commerce 2018: a managerial and social networks perspective, (Springer, 2017)

11. E. Turban, J. Whiteside, D. King, Outland, Introduction to electronic commerce and social commerce, (Springer, 2017) https://link.springer.com/content/pdf/10.1007/9783-319-50091-1.pdf

12. G. Xu, Y. Cao, Y. Ren, X. Li, Z. Feng, Network security situation awareness based on semantic ontology and user-defined rules for Internet of Things, IEEE Acc. 5, 2104621056, (2017) https://ieeexplore.iee.org/abstract/document/7999187

13. G. Zhang, J. Cheng, Analysis of the Impact of Interest Rate Liberalization on Internet Finance, Soc. Sci. 7, 6, 248, (2018) https://www.semanticscholar.org/paper/Analysisof-the-Impact-of-Interest-Rate-on-Internet-ZhangCheng/5596c0c2897c435147f15af9c43df3e2907946ab

14. Q. Zhou, J. Luo, The study on evaluation method of urban network security in the big data era, Intel. Auto. \& Soft Comp. 1-6, (2017) https://doi.org/10.1080/10798587.2016.1267444 